\title{
Perancangan Sistem Pendukung Keputusan Penerimaan Siswa Baru Dengan Menerapkan Metode Composite Performance Index(cpi) (studi kasus: SDN 101864 Gunung Rintih)
}

\section{Article Info \\ Article history:}

Received 12 Augustus, 2021

Revised 20 September, 2021

Accepted 01 October, 2021

\section{Keywords:}

Decision Support System, New Student Admission, Composite Performance Index (CPI)

\begin{abstract}
Decision support system is part of a computer-based information system that is commonly used to support decision making in an organization or company. Decision support systems can be generated using several methods, one of which is the Composite Performance Index (CPI) method. Composite Performance Index is a composite index that can be used to determine the determination or ranking of various alternatives based on several criteria. By using this Composite Performance Index, it is hoped that the process of admitting new students is more effective and efficient so that students quickly get information about whether or not the prospective student is accepted and the results are in accordance with the expected results.
\end{abstract}

This is an open access article under the CC BY-SA license.

\section{Corresponding Author: \\ Robertus Siahaan}

ITMI, Information Systems, Medan, Indonesia

Email Address: reberto@gmail.com

(C) 2021 The Author: Published by. Cattleya Darmaya Fortuna

\section{Pendahuluan}

Penerimaan siswa baru merupakan salah satu proses yang ada di instansi pendidikan untuk menyaring calon siswa yang terpilih sesuai kriteria yang ditentukan [1]. Pada umumnya, proses penerimaan siswa baru terdiri dari proses pendaftaran, proses penyeleksian, pengumuman siswa baru yang diterima, dan proses penyelesaian administrasi [2]. Proses administrasi juga cenderung lambat, karena data belum terintegrasi dan terkelola dengan baik. Proses ini juga masih menggunakan arsip dalam bentuk fisik yang rentan mengalami kerusakan atau bahkan hilang [3]. Hal ini menimbulkan masalah, yaitu kegiatan penerimaan siswa terlaksana kurang efisien dan memungkinkan terjadinya pengulangan data yang sama [4]. Salah satu upaya untuk memperbaiki proses PSB dan meningkatkan pelayanan kepada calon siswa, maka dibutuhkan sebuah sistem yang dapat melakukan proses PSB [5] bagi pihak sekolah. 


\section{Robertus Siahaan}

doi.org/10.54209/jatilima. V3i2.148

Sistem ini dibangun dengan menggunakan metode Composite Performance Index (CPI) [6]. Perangkat lunak ini berfungsi untuk mempermudah proses pendaftaran siswa baru yang selama ini masih menggunakan dokumen kertas dan Microsoft Excel [7]. Metode Composite Performance Index adalah metode yang didasarkan pada indeks kinerja gabungan dari berbagai alternatif terhadap kriteria yang tidak seragam [8]. Composite Performance Index (CPI) juga merupakan salah satu metode perhitungan pengambilan keputusan berbasis indeks gabungan kinerja yang dapat digunakan untuk menentukan peringkat atau rangking dari berbagai alternatif berdasarkan beberapa kriteria, walaupun kriterianya berbeda-beda [9]. Composite Performance Index (CPI) adalah metode yang umum digunakan dalam proses pengambilan keputusan) [10]. Sehingga sistem pendukung keputusan sangat diperlukan untuk dapat menyelesaikan permasalahan ini. Sistem pendukung keputusan merupakan suatu sistem yang mampu memecahkan masalah secara efesian, efektif, yang bertujuan untuk membantu pengambilan keputusan dengan memilih berbagai alternatif keputusan [11]. Sistem pendukung keputusan memberikan suatu keputusan yang bersifat semiterstruktur, dimana tidak seorangpun tahu secara pasti bagaimana keputusan seharusnya dibuat [12]. SPK bertujuan untuk menyediakan informasi, membimbing, memberikan prediksi serta mengarahkan kepada pengguna informasi agar dapat melakukan pengambilan keputusan dengan lebih baik [13]. Sistem pendukung keputusan tidak dimaksudkan untuk menggantikan peran pengambil keputusan, tapi untuk membantu dan mendukung pengambil keputusan [14]. Berdasarkan pengujian yang dilakukan, sistem yang dibuat mampu memberikan hasil yang baik sesuai dengan perhitungan yang digunakan, membantu mempercepat dalam mengambil keputusan [15].

\section{Metode}

Dalam penyeleksian siswa baru dengan menggunakan metode Composite Performance Index (CPI) diperlukan kriteria-kriteria dan bobot untuk melakukan perhitungannya sehingga akan didapat alternatif terbaik, dalam hal ini alternatif yang dimaksud adalah Peserta didik yang diterima. Kebutuhan informasi merupakan kebutuhan yang ada pada sistem dan informasi yang dihasilkan oleh sistem. Berikut ini adalah tabel hasil perhitungan CPI dengan mengurutkan berdasarkan nilai tertinggi.

Tabel 1. Hasil Penghitungan CPI

\begin{tabular}{cllcc}
\hline No & Id_calon & \multicolumn{1}{c}{ Nama } & Nilai CPI & Peringkat \\
\hline 1 & C001 & Amelia Perbina Br Ginting & 204,9 & 1 \\
2 & C002 & Ananda Pintar Bargi Br Barus & 190,9 & 2 \\
3 & C006 & Andini Aminarti & 182 & 3 \\
4 & C008 & Anggie Br Sembiring & 166,9 & 6 \\
5 & C005 & Aprilya Ersiviola Br Sembiring & 100 & 9 \\
6 & C009 & Ardiah Syah & 182 & 4 \\
7 & C004 & Astriana Aini & 11,1 & 8 \\
8 & C003 & Attahanaya Claudia Noveliza & 124 & 7 \\
9 & C007 & Lubis & 77,1 & 10 \\
10 & C010 & Bela Adelina Br Tarigan & 180 & 5
\end{tabular}




\section{Robertus Siahaan}

doi.org/10.54209/jatilima. V3i2.148

Hasil nilai yang dicapai lebih rendah tidak mencapai nilai kriteria karena hasil nilai cpi yang lebih besar dialah yang akan diterima sebagai siswa baru. Siswa yang diterima dan nilai yang paling tertinggi ke rendah Attahanaya Claudia Chania Dwi Marsha $\mathrm{Br}$ Barus, Ardiah Syah Noveliza Lubis, Amelia Perbina Br Ginting, Ananda Pintar Bargi Br Barus, Anggie Br Sembiring, Andini Aminarti, Bela Adelina Br Tarigan.

\section{Use Case Diagram}

Use case diagram digunakan untuk menjelaskan alur interaksi antara pengguna dengan sistem.

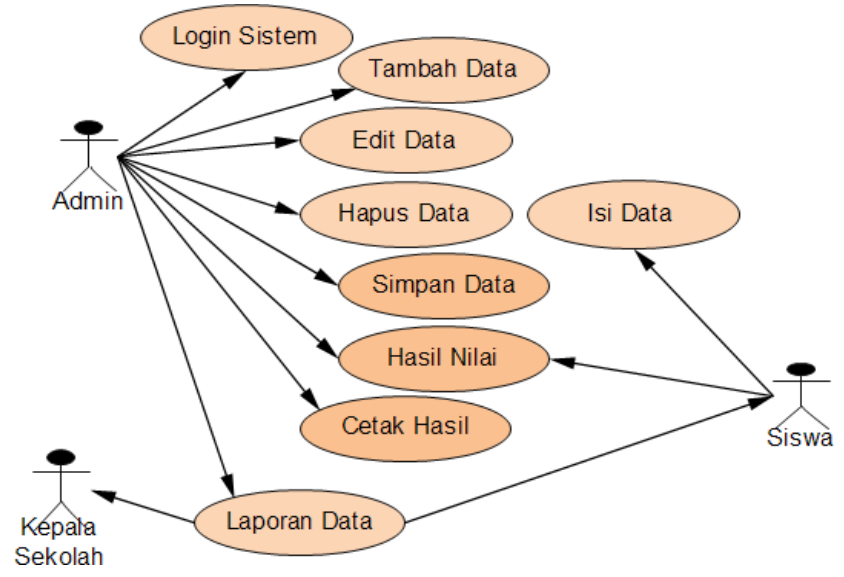

Gambar 1. Use Case Diagram

\section{Activity Diagram}

Activity Diagram digunakan untuk menggambarkan menu-menu yang terdapat pada sistem serta alur perintah penekanan tombol pada sistem.

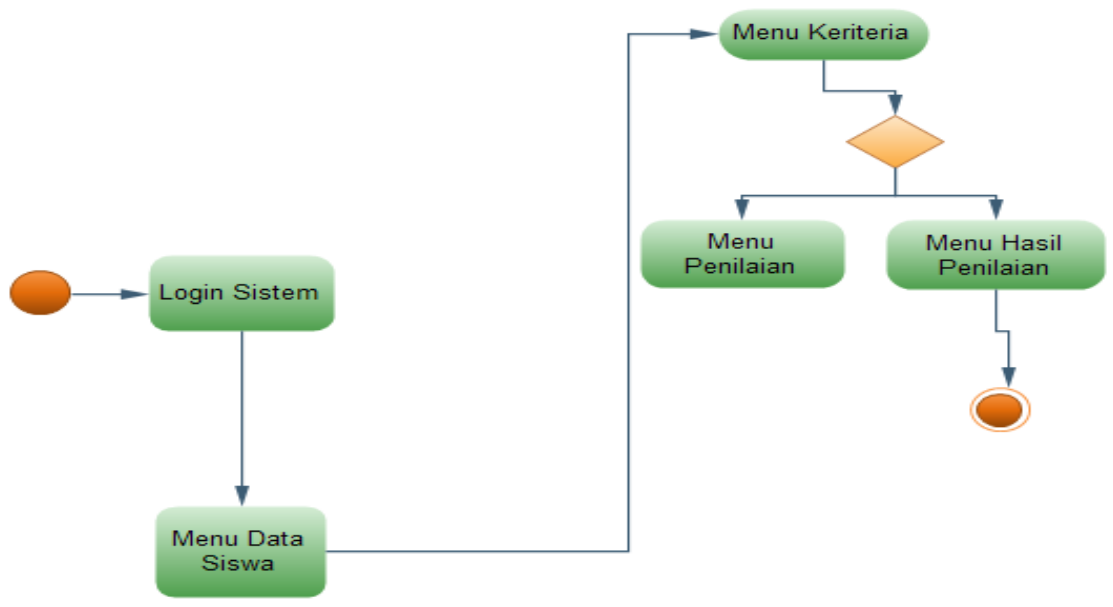

Gambar 2. Activity Diagram

\section{Sequence Diagram}

Sequence diagram biasa digunakan untuk menggambarkan skenario atau rangkaian langkah-langkah yang dilakukan sebagai respons dari sebuah event untuk menghasilkan 


\section{Robertus Siahaan}

doi.org/10.54209/jatilima. V3i2.148

output tertentu.

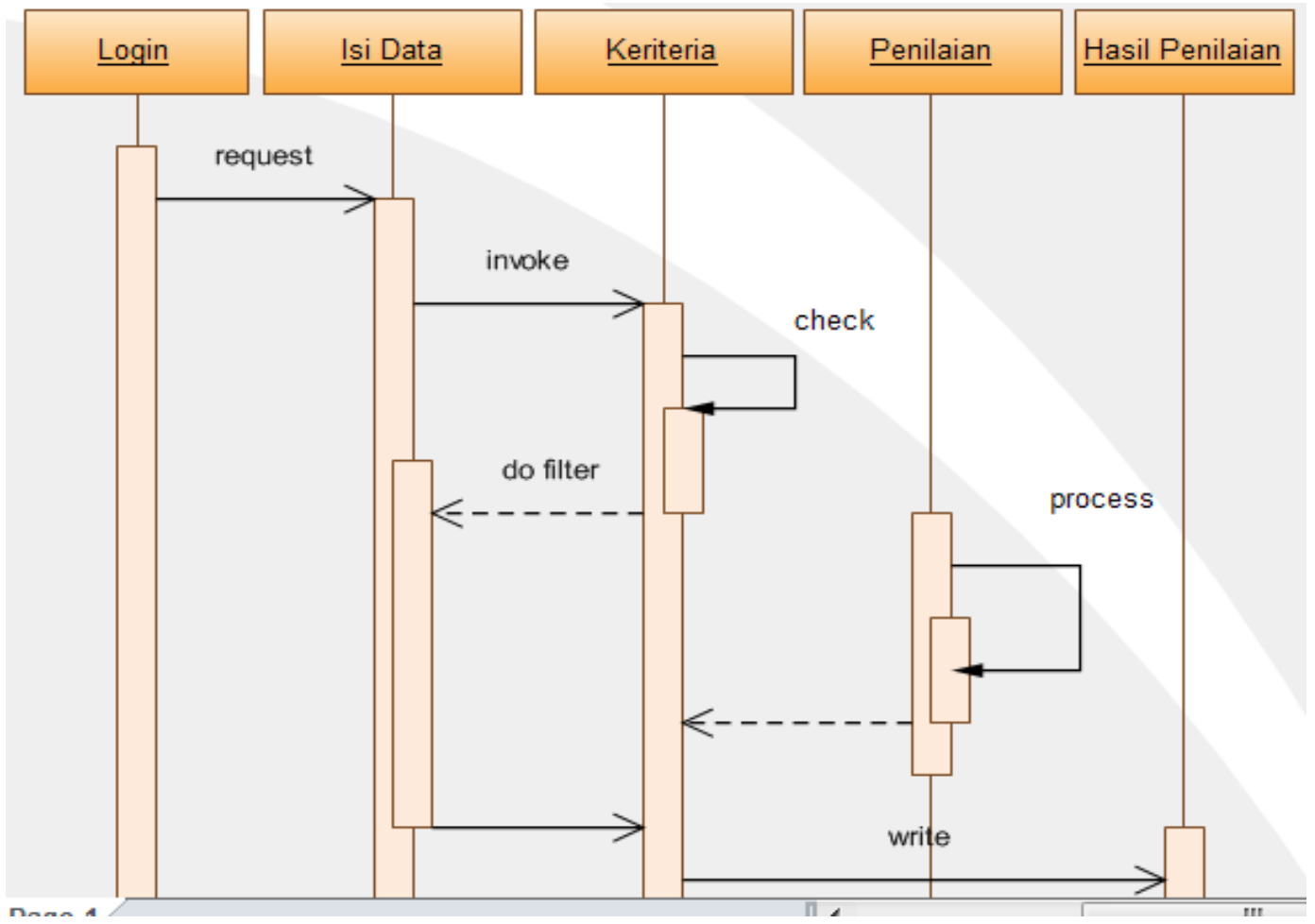

Gambar 3. Sequence Diagram

Spesifikasi perangkat yang dibutuhkan yaitu:

1. Prosesor Intel Pentium Dual-Core $2.4 \mathrm{GHz}$. Minimal atau yang lebih tinggi

2. Memory $512 \mathrm{Mb}$ Minimal atau yang lebih tinggi

3. Harddisk minimal $40 \mathrm{~Gb}$ dengan freespace $500 \mathrm{MB}$. Minimal atau yang lebih tinggi

4. VGA card $64 \mathrm{MB}$ atau yang lebih tinggi

5. Keyboard dan Mouse

6. $M y S Q L$

7. Microsoft Visual Basic Net.2008

\section{Hasil dan Pembahasan}

Algoritma merupakan langkah-langkah atau cara yang dilakukan untuk menyelesaikan atau menerangkan sesuatu hal yang akan dilakukan. Dalam skripsi ini penulis membuat algoritma untuk menjelaskan atau menerangkan kepada pembaca bagaimana sistem yang dibangun dapat berjalan. Adapun langkah-langkahnya adalah :

1. Algoritma Kriteria yang dibutuhkan

Input: Xij (min) Nilai alternatif ke-i

$\mathrm{Xij}(\max ) \longrightarrow \quad$ Nilai alternatif ke-j

Output: Aij Nilai Alternatif

Proses: $\mathrm{Aij}=\mathrm{Xij}(\mathrm{min}) / \mathrm{Xij}(\mathrm{min}) * 100$ (Nilai alternatif ke-I dibagi nilai alternatif ke-j).

2. Algoritma Bobot dan Tren

Input: $X(\mathrm{i}+1 . \mathrm{j}) \longrightarrow$ Nilai Alternatif ke-i+1 


\section{Robertus Siahaan}

doi.org/10.54209/jatilima. V3i2.148

$X i j(\min ) \longrightarrow \quad$ Nilai Alternatif ke-i

Output: $\mathrm{A}(\mathrm{i}+1 . \mathrm{j}) \longrightarrow$ Nilai alternatif $\mathrm{ke}-\mathrm{i}+1$

Proses: $A(i+1 . j)=X(i+1 . j) / X i j(m i n)$

3. Algoritma Penghitungan Manual

Input: Aij $\longrightarrow$ Nilai alternatif ke-i

$\mathrm{Pj} \longrightarrow$ Bobot kepentingan Kriteria ke-j

Output: Iij $\longrightarrow$ Nilai Kriteria ke-I pada Kriteria ke-j

Proses: $\mathrm{Iij}=\mathrm{Aij} * \mathrm{Pj}$

(Nilai alternatif ke-I dikali bobot kepentingan Kriteria ke-j)

4. Alogartima Perhitungan Id_calon C001

Input: $\mathrm{Ij}=$ eqv jn Iij (Nilai Keriteria 1,2,3.

Output: Indeks alternative Ke-I

Proses: nilai_kriteria_1 $*$ bobot + nilai_kriteria_ $2 *$ bobot + nilai_kriteria_3 $*$ bobot + nilai_kriteria_4 $*$ bobot + nilai_kriteria_5 $*$ bobot

\section{Implementasi Program}

Dalam Implementasi sistem pendukung keputusan untuk menentukan penerimaan siswa baru mencakup spesifikasi kebutuhan perangkat keras (hardware) dan spesifikasi perangkat lunak (software). Implementasi merupakan langkah yang digunakan untuk mengoperasikan sistem yang dibangun. Dalam bab ini dijelaskan bagaimana menjalankan sistem. Sistem pengolahan program merupakan suatu kesatuan pengolahan yang terdiri dari prosedur dan pelaksanaan data. Komputer sebagai sarana pengolahan program haruslah menyediakan fasilitas-fasilitas pendukung dalam pengolahan nantinya. Berikut hasil akhir tampilan aplikasi dalam menetukan penerimaan siswa baru dapat dilihat pada Gambar 4.

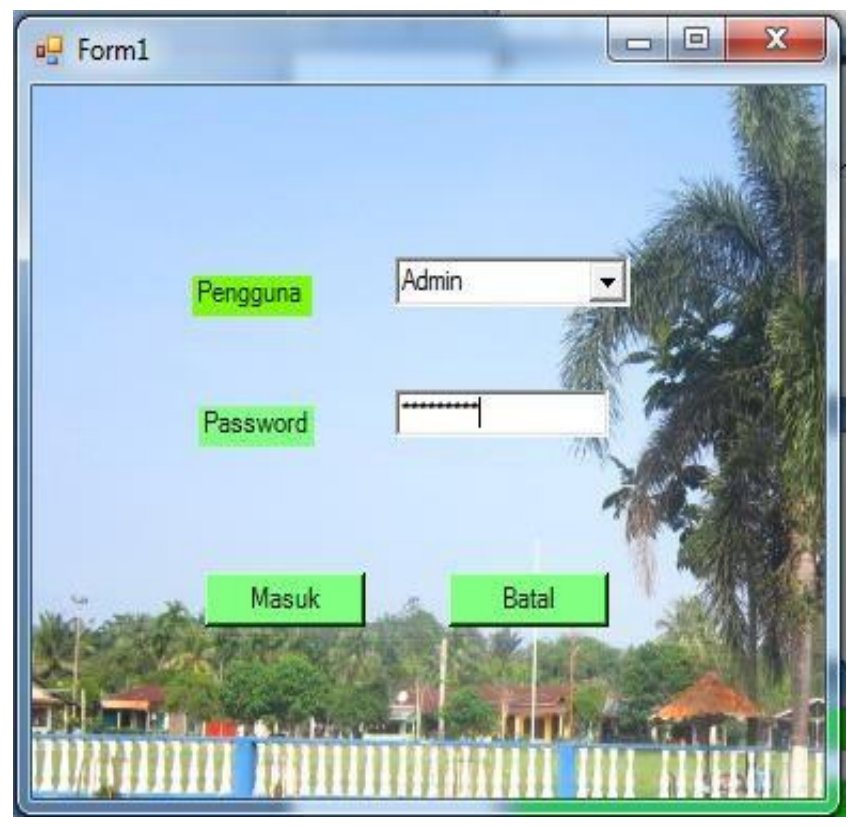

Gambar 4. Sequence Diagram 


\section{Robertus Siahaan}

doi.org/10.54209/jatilima. V3i2.148

Tampilan menu utama digunakan untuk menampung semua pilihan-pilihan menu dan sub menu dalam sistem.

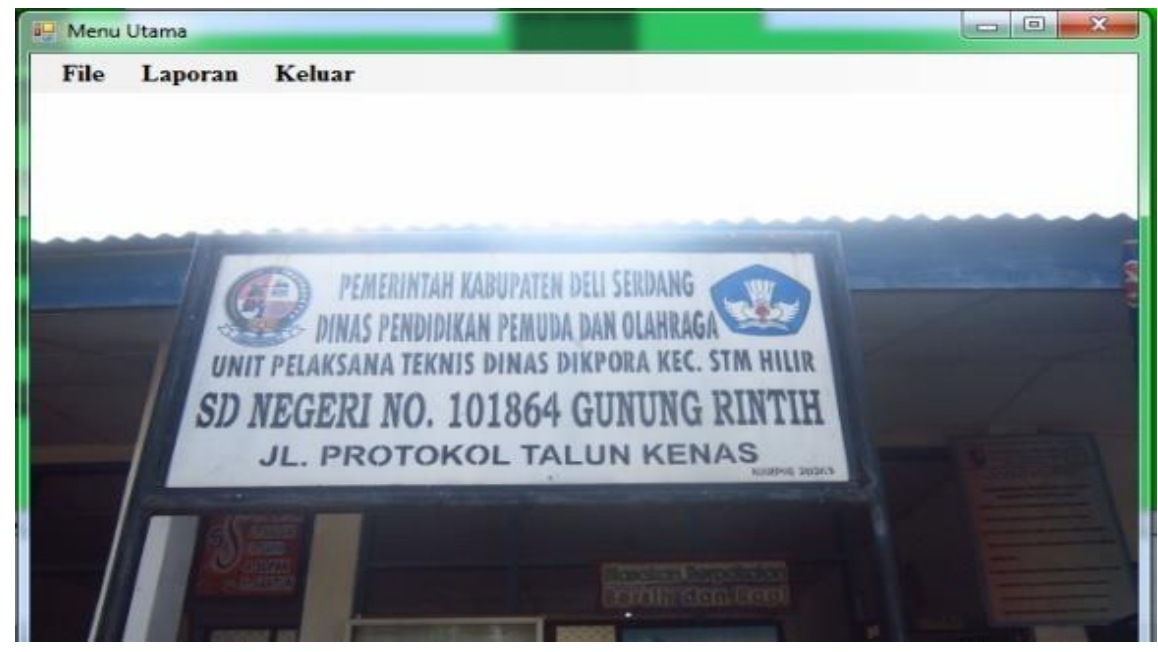

Gambar 5. Form Menu Utama

Pada form inilah Data siswa ditentukan dan pada form ini juga data siswa dapat diperbaiki atau diedit apabila terjadi kesalahan pada saat penginputan data atau nilai siswa.

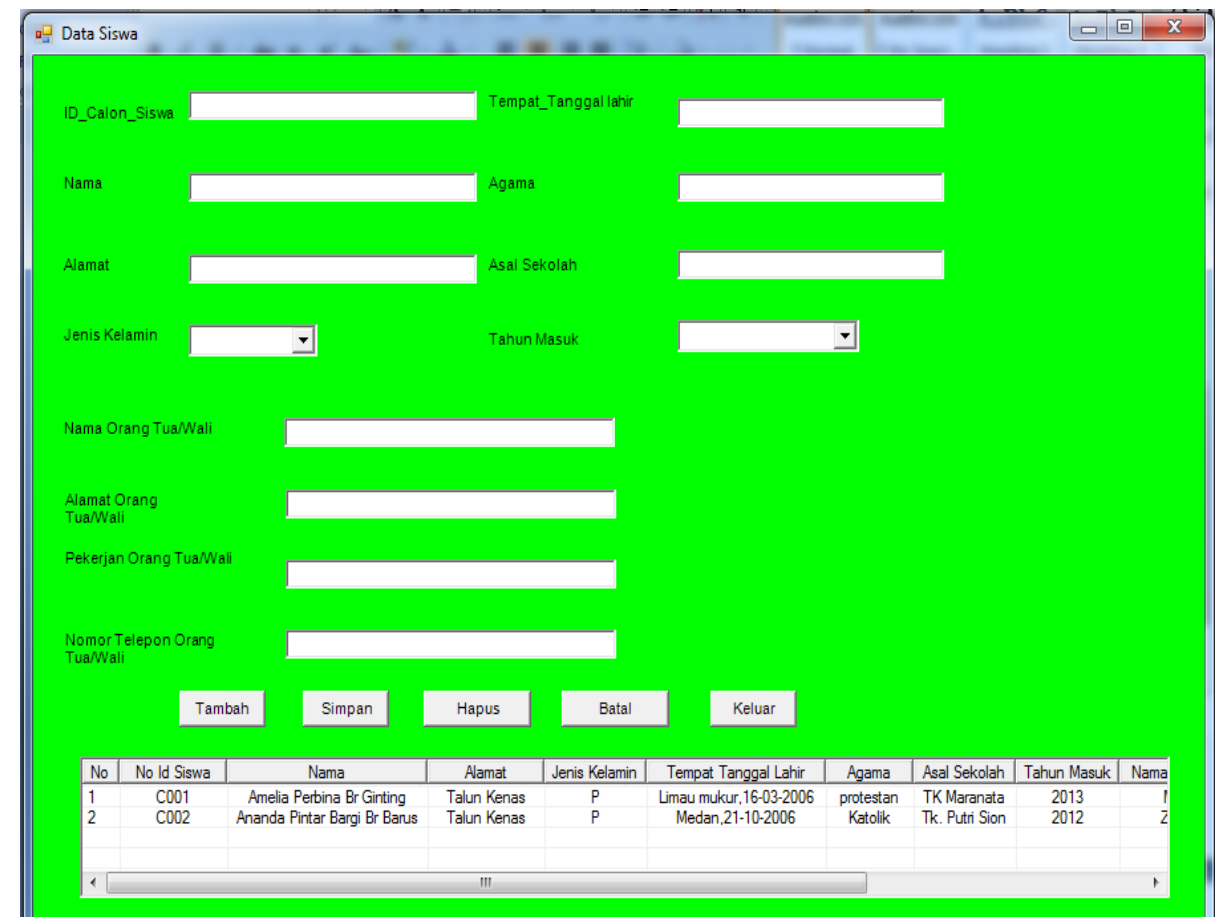

Gambar 6. Form Data Siswa

Form ini berfungsi untuk proses seleksi untuk menentukan nilai presentase dari skala penilaian yang ada. 


\section{Robertus Siahaan}

doi.org/10.54209/jatilima. V3i2.148

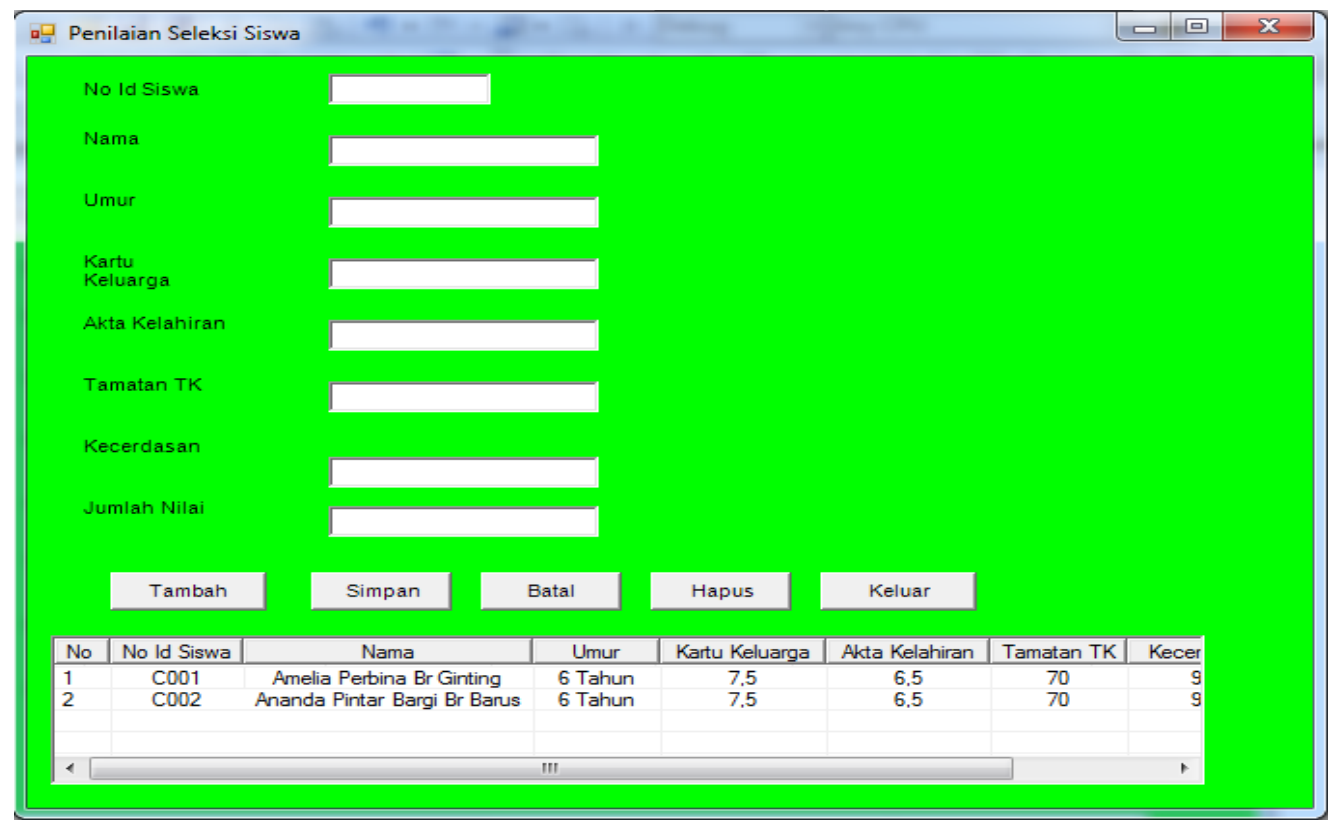

Gambar 7. Form Penilaian Seleksi Siswa

Form ini berfungsi sebagai data menu Hasil Penilaian menentukan hasil penilaian dalam penyeleksian calon siswa baru.

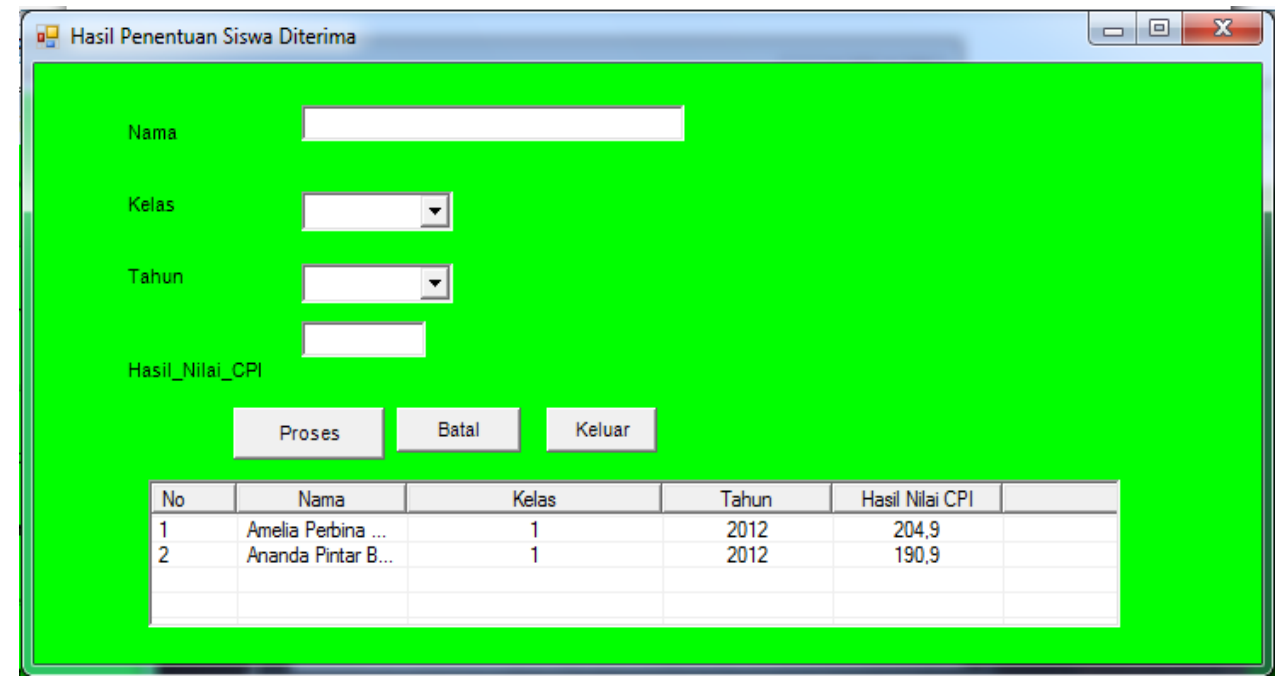

Gambar 8. Form Hasil Penilaian Seleksi Siswa

\section{Kesimpulan}

Adanya kesimpulan dan saran ini dapatlah diambil suatu perbandingan yang akhirnya dapat memberikan perbaikan- perbaikan pada masa yang akan datang. Adapun kesimpulan yang penulis peroleh adalah sebagai berikut: Sistem pendukung keputusan yang dibangun dapat mempermudah staff panitia seleksi ujian untuk mempercepat proses penyeleksian dan penerimaan siswa di SD Negeri No.101864 


\section{Robertus Siahaan}

doi.org/10.54209/jatilima. V3i2.148

Gunung Rintih. Dengan adanya sistem pendukung keputusan dapat meminimalisir kesalahan dan penerimaan siswa secara subyektif. Sistem pendukung keputusan yang dibangun dapat memberikan informasi yang cepat tentang penerimaan serta penyeleksian pada SD Negeri No.101864 Gunung Rintih.

\section{Reference}

[1] A. S. Zain and R. Purniawati, "Sistem Pendukung Keputusan Penerimaan Siswa Baru dengan Metode Simple Additive Weighting," Sains, Apl. Komputasi dan Teknol. Inf., vol. 2, no. 1, 2020.

[2] J. M.Kom, "SISTEM INFORMASI PENERIMAAN SISWA BARU BERBASIS WEB DI SEKOLAH MENENGAH PERTAMA NEGERI 43 PALEMBANG," $J$. Digit. Teknol. Inf., vol. 1, no. 2, 2020.

[3] H. H. Solihin, "PERANCANGAN SISTEM INFORMASI PENERIMAAN SISWA BARU BERBASIS WEB (STUDI KASUS : SMP PLUS BABUSSALAM BANDUNG)," Infotronik J. Teknol. Inf. dan Elektron., vol. 1, no. 1, 2017.

[4] F. Hanifah and A. Fatmawati, "Sistem Informasi Penerimaan Siswa Baru Madrasah Ibtidaiyah Program Khusus Kartasura,” Emit. J. Tek. Elektro, vol. 20, no. 02, 2020.

[5] Yunita, Maruloh, and S. Wulandari, "Rancang Bangun Sistem Informasi Penerimaan Siswa Baru Pada SMP Yanuri Jakarta,” Pros. SIMNASIPTEK, vol. 12, no. 2, 2017.

[6] A. A. Tri Susilo and M. Putri, "Sistem Pendukung Keputusan Pemberian Reward Kepada Karyawan Bandar Udara Silampari Lubuklinggau Menggunakan Metode Composite Performance Index(CPI)," J. Komput. Terap., vol. 2, no. 2, 2016.

[7] R. A. Herdianto, "Analisis Dan Pengembangan Sistem Informasi Penerimaan Siswa Baru Berbasis Codeigniter Php Framework Di Smk Ma'Arif 1 Mungkid," Lumbung Pustaka UNY, no. 1, 2020.

[8] L. Sarumaha, B. Efori, A. H. Sihite, and D. P. Utomo, "Sistem Pendukung Keputusan Penempatan Mentor Pada Pusat Pengembangan Anak IO 558 Sangkakala Medan Menggunakan Metode CPI dan ROC," KOMIK (Konferensi Nas. Teknol. Inf. dan Komputer), vol. 4, no. 1, 2020.

[9] A. Nugroho and N. Bahtiar, "SISTEM PENDUKUNG KEPUTUSAN PENENTUAN NILAI KENAIKAN PANGKAT TNI ANGKATAN DARAT MENGGUNAKAN METODE COMPOSITE PERFORMANCE INDEX (CPI)," MATEMATIKA, vol. 19, no. 3, 2016.

[10] A. A. T. Susilo, "Penerapan Metode CPI Pada Pemilihan Hotel Dikota Lubuklinggau," J. RESTI, vol. 1, 2017.

[11] Sriani and R. A. Putri, "Analisa Sistem Pendukung Keputusan Menggunakan Metode Topsis Untuk Sistem Penerimaan Pegawai Pada Sma Al Washliyah Tanjung Morawa," J. Ilmu Komput. dan Inform., vol. 02, no. April, 2018.

[12] F. I.-R. P. Computer, "Sistem Pendukung Keputusan Penerimaan Jurnalis Menerapkan MultiObjective Optimization On The Basis Of Ratio Analysis (MOORA)," JURIKOM (Jurnal Ris. Komputer), vol. 5, no. 1, 2018.

[13] S. W. Sari and B. Purba, "Sistem Pendukung Keputusan Pemilihan Ketua Danru Terbaik Menggunakan Metode ARAS," Semin. Nas. Teknol. Komput. Sains SAINTEKS 2019, 2019. 


\section{Robertus Siahaan}

doi.org/10.54209/jatilima. V3i2.148

[14] Y. Zai, Mesran, and E. Buulolo, "Sistem Pendukung Keputusan untuk Menentukan Buah Rambutan Dengan Kualitas Terbaik Menggunakan Metode Weighted Product (WP)," Media Inform. Budidarma, vol. 1, no. 1, 2017.

[15] M. R. Noviansyah, W. Suharso, D. R. Chandranegara, M. S. Azmi, and M. Hermawan, "Sistem Pendukung Keputusan Pemilihan Laptop Pada E-Commerce Menggunakan Metode Weighted Product," Pros. SENTRA (Seminar Teknol. dan Rekayasa), vol. 0, no. 5, 2019. 